\title{
Public Domesticity - Digital Fabrication and Design-Build in Detroit
}

\section{TSZ YAN NG}

University of Michigan

[F]orensis is used to interrogate the relation between the two constitutive sites of forensics-namely fields and forums. In forensic terms the division is straightforward; the field is the site of investigation and the forum is the place where the results of an investigation are presented and contested. However, both these sites must be understood to be more than mere locational designations. The field is not only a neutral, abstract grid on which traces of a crime can be plotted out, but itself a dynamic and elastic territory, a force field that is shaped by but also shapes conflict. The forum, in turn, is a composite apparatus. It is constituted as a shifting triangulation between three elements: a contested object or site, an interpreter tasked with translating "the language of things," and the assembly of a public gathering. Forensis thus establishes a relation between the animation of material objects and the gathering of political collectives.

\section{-Eyal Weizman, in the introduction of Forensis ${ }^{1}$}

\section{INTRODUCTION}

Long contested in architectural and artistic discourse, the domestic space of the single-family home has been addressed as a shaper of social habits, cultural identity, and, more recently, as the driver of economic stability. In Detroit (as well as in other post-industrial cities), a recent phenomenon has emerged where such single-family homes - sold cheaply at auction - are rescued and transformed into artist residencies. Operated and managed by artists, these residencies constitute a form of social practice. Architecturally, these artists assume the role of the DIY builder, fixing and renovating the homes to welcome artists both local and international. Collectively, these residencies have affected not only the physical landscape of the city, but also have facilitated social interaction opposite that suggested by private residences. What was once formerly private is now made public.

Taking this phenomenon as a point of departure, this yearlong thesis course (M. Arch level) examines constructs of "public" and "domesticity" against broader histories of artistic, architectural, and urban design practices. Of special note is the emergent nature of social engagement. Can practices like the single-family home-based residency foster community engagement? How can we envision the morphology of the single-family home in Detroit, particularly in relation to Detroit's troubled economy? How are the roles of architects/ designers redefined? Pedagogically, beyond a question of

\author{
WES MCGEE \\ University of Michigan
}

making for the design-build component, how do we integrate digital fabrication processes in making? What is digital crafting and how do material explorations inform design decisions? At a one-to-one scale of production, can digital fabrication be integrated into a design-build curriculum that enhances exploratory processes in making - including prototyping as a form of tacit knowledge - and simultaneously offer the students the opportunity to gain competency with techniques and workflow processes?

Partnering with Popps Packing, a non-profit group that has one of the longest running residency programs in Detroit, our collaboration focuses on their future planning of the Back Forty, the overgrown, unused alleyway behind their residency. Back Forty aims to convert existing backyard garages and sheds into community art studios for craft, printing, ceramics production, woodworking, and community gardening. This area along with Popps Packing's various residency buildings serves as the site for our design-build explorations. Our partnership saw the value of linking with an existing community in Detroit, where the projects, after completion, will have a second life for the residency's use.

\section{COURSE STRUCTURE AND METHODOLOGY}

The overall intention of this course was to integrate social research with design-based initiatives as a unique model of hands-on engagement with communities, with a full-scale design-build experience as a comprehensive pedagogy. The fall seminar was joint-taught with art historian Joan Kee. The interdisciplinary teaching brings together students in art history and architecture to discuss topics and issues including; history of the city of Detroit and artist residencies, public/ common(s) versus private/property, questions of social practice and the space of participation, boundaries both conceptual and physical, and morphology of domestic homes as singular entity and collectively as neighborhoods. A design proposal at the end of the term positions their theoretical and making objectives for the following term's design-build studio.

During the design-build studio, given the emphasis on making, architecture students were also enrolled in Wes McGee's Advanced Digital Fabrication Seminar to explore computational design workflows and digital fabrication processes. Each team focused on a specific material and technique for exploration, developing their design through prototyping and regular design reviews with our Detroit partner. Each team was provided with a small budget for material and fabrication 




Figure 1: Boundary condition between the City of Detroit (upper half), and Hamtramck (lower half) along Carpenter Street, showing comparative study of residential fabric in terms of density and scale with foreclosed and blighted properties highlighted.

funded by a Michigan Mellon Course Grant. ${ }^{2}$ The students who balloted for this thesis section did not have to have prior experience with digital fabrication or design-build expertise. Part of the "learning through prototyping" pedagogy was to develop crafting techniques specific to the material being used and to hone building construction knowledge based on their design proposal. Another goal of the design studio was to use prototyping as a way to develop the facility to move between different computational processes for design along with fabrication workflows and the material realities of assembly and construction. Issues of tolerance became a key factor for iterative prototyping, especially when it came to detailing connections for desired aesthetics and performative criteria. On-site installation processes such as performing site survey and preparation were also part of the design-build pedagogy. The students were divided into teams of two with a total of six teams. Two teams decided to collaborate to both share the labor involved in the production as well as to work with each other to reinforce their respective design intentions.

\section{FORENSIS ON DETROIT AND HAMTRAMCK - BOUNDARY CONDITIONS}

Detroit, approximately forty miles from University of Michigan, calls to mind numerous associations culturally, economically, and politically. Research conducted during the seminar highlighted not only the spatial consequences of the city in relation to burgeoning automotive manufacturing during the early to mid-20th Century, but also the contested dynamics in the second half of the century played out in regards to racial, social, and economic segregation reinforced by uneven distribution of power and wealth. Rather than operating with broad claims about the city, to familiarize the students with more precise understanding of Detroit, the students conducted research on the history of Detroit and Hamtramck, Hamtramck being the two-mile radius city surrounded by Detroit where Popps Packing is partially situation. The research on the city of Detroit and Hamtramck culminated with an annotated timeline of its history with key moments of development as well as maps generated with GIS data on zoning and building typologies, the periods of developed, and more recent phenomena of foreclosures and blighted properties.

The research and maps generated were not about visualizing and proving the hollowing of the city over the years due to blight, but rather, a deeper understanding of how policies and its constituents, the force fields of forums, bear direct consequences onto the physical landscape of the city. A zoomed in view of the border of Hamtramck and Detroit along Carpenter Street where Popps Packing is located is case in point (figure 1). Over the years, Popps Packing has acquired adjacent buildings and properties next to their main building through the 


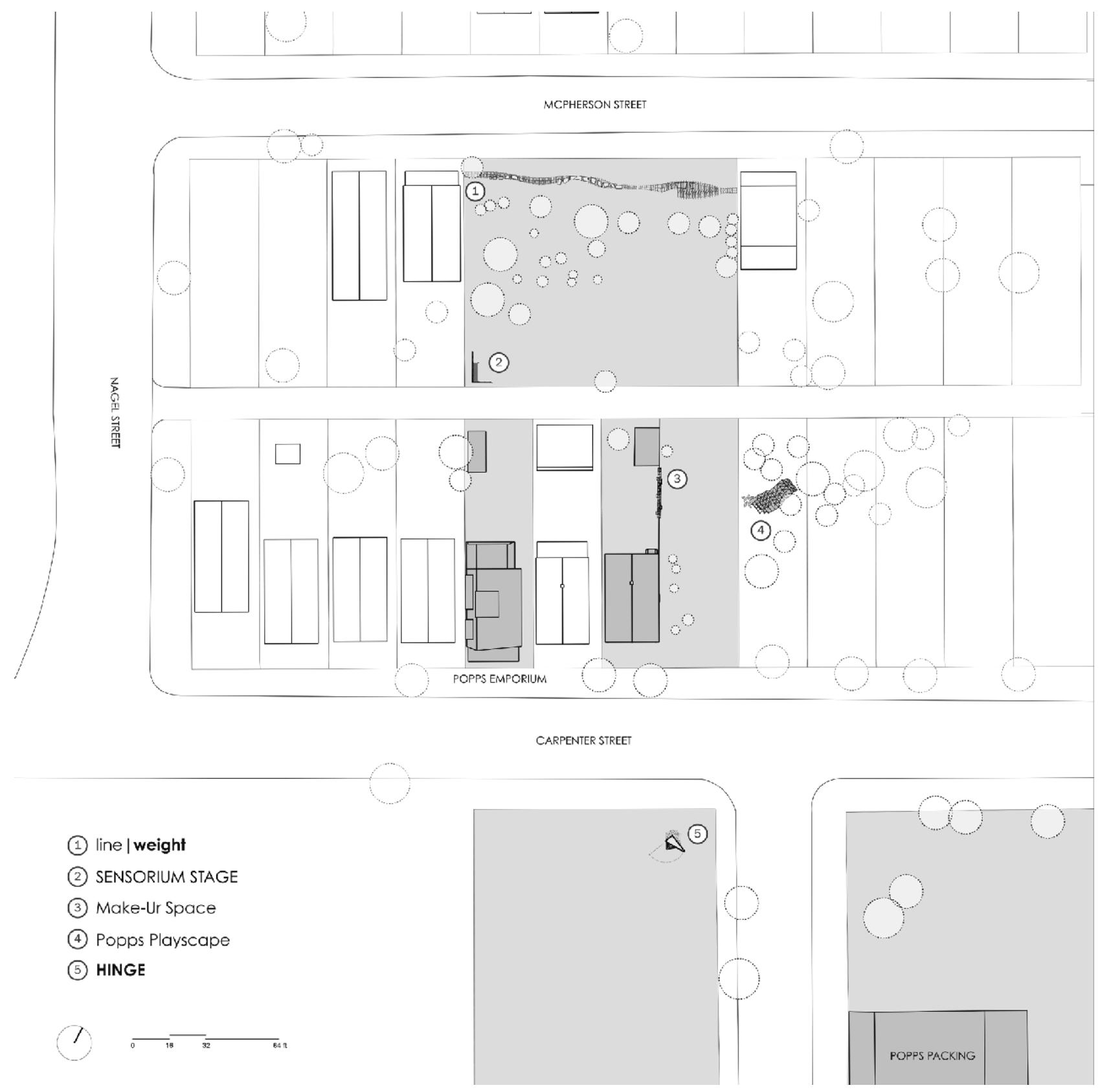

Figure 2: Site plan location of the projects.

city's auction process. Popps Packing's overall complex currently straddles both sides of Carpenter Street. In comparing the Northern Detroit side against the Southern Hamtramck half, there's a stark contrast in density between the two residential neighborhoods. The blocks on the Detroit side is visibly more hollowed where proportionately some actually have more open empty lots than buildings on it. Compared with the southern half, while there might still be pockets of fields where once a house stood (most often, the foundation is still below ground), it is far more cohesive as a residential neighborhood of smaller buildings with less foreclosed and blighted properties. A main reason for this contrast is that Hamtramck was originally developed as an enclave for immigrant workers in the auto industry. The homes were built modestly and have since been occupied by rotating group of immigrants, initially being Polish and most recently, with a large community of Bangladeshis. These first wave immigrant groups, unlike the wealthier middle class, did not relocate to the suburbs or become part of the 'white flight' that moved out of Detroit. These tight-knit communities provided anchor and a tax base for Hamtramck, allow the city to maintain its own police and municipal services such as garbage collection. 


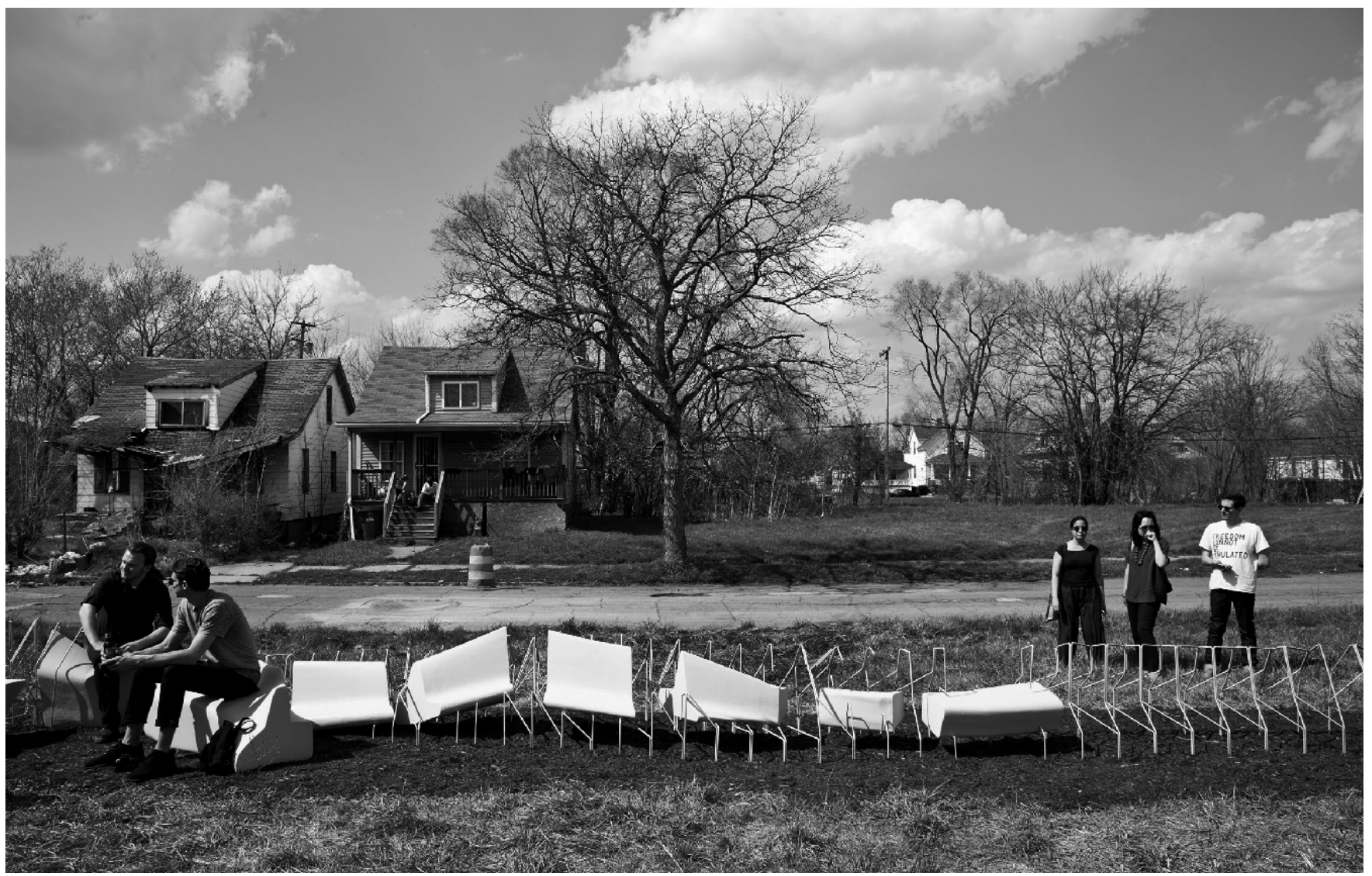

Figure 3: Line Weight, robotically bent steel fence and hot-wire cut coated foam units

Additional to the research on the city of Detroit and Hamtramck, precedents were examined in the seminar including; Granby Street by the UK collective Assemble, Listening \& Archive House by Theaster Gates in Chicago, numerous artist converted houses in Detroit such as Power House, Sound House, Play House, and Squash House by Design 99, and other creative residencies such Zimbabwean Cultural Center of Detroit (ZCCD) and Write House. In the examination of these precedents, the house is more than the object or material artifact of manipulation. Rather, the house is both the fields and forums by which activities are generated, animated, and tested. The investigation of domestic artist residencies in Detroit offers an alternative model to examine the city, one that is more emergent and bottom-up compared to other monolithic examination of Detroit according to socio-political or socio-economic data. In this case, the involvement with Popps Packing was more than architects and designers being 'consultants,' offering services or advice. The thesis group refrained from the language of referring to Popps Packing as 'clients.' Instead, it was intended as a collaboration which places the onus and responsibility of involvement and participation on all parties. This included Graem Whyte, one of the founders of Popps Packing, who was involved in design review discussions regularly throughout the year and also during the installation process. This working relationship not only ensured that everyone was kept abreast of all decisions being made but also eliminates the sense that a large institution located in Ann Arbor is making top-down decisions that are inappropriate and/or insensitive to the politics and contingencies that are specific to the place and its people.

Beyond the pragmaticism of designing for the 'needs' of the artist residency and their intended programming, the concept and reality of boundary conditions allowed the students to articulate a more situated position in their architectural design inquiry. Precedents examined during the seminar focused on issues of boundaries not as dividing conditions but as connectors where exchanges and inhabitation are possible. Degrees of connection/separation through porosity as design parameters sought to modulate the types of activities being proposed, especially to reinforce notions of exchange and promote the outward reach of the residency to its community for various types of public programming. More than a design-build project that is simply robust in its construction for everyday use, the designsconsider the nuances of an acculturated sense of boundary in both how one encounters the built environment and what cues are necessary to encourage participation for various types of activities. The specificity of audience was of key concern. This consideration ranges anywhere from different ages to cultural background. Beyond those that are already associated with the residency, the audience may include neighbors both friendly and unsavory. As such, boundary was more than separation and connection. The 


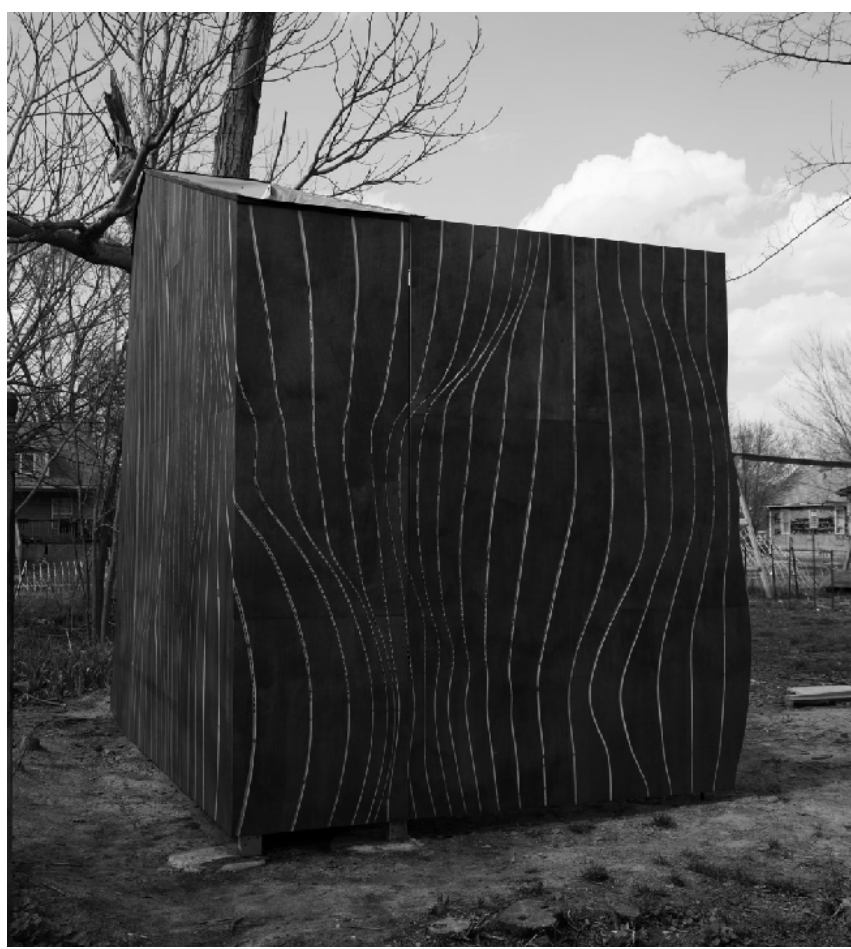

Figure 4: Sensorium Shed

designs aimed to actively engage all the possible contingencies in context and simultaneously present alternative options for undermining fixed notions of how boundary conditions operate. Boundary crossing or inhabitation was dealt with at different scales, at the city level between Detroit and Hamtramck, as well as on site, between implied and explicit relations of objects/ artifacts and activities.

\section{FIELDS AND FORUMS, 3 PROJECTS}

Through Weisman's definition of Forensis, the students not only interrogated the sites of Detroit, of fields and forums, but enacted within them through their design-build projects. Three out of the five team projects from the course are highlighted here. (Projects numbered 1, 2, and 3 in the plan.) See figure 2 . All work was designed, fabricated, and installed by the students. There were three key learning objectives for the design-build course. The first one relates to the execution of the projects; from managing a budget, to meeting a production schedule, to sourcing materials, to the installation on-site. The second has to do with the heuristic knowledge that comes through prototyping. Digital models often allow design students to ignore basic concepts such as gravity, balance, and material behavior. Prototyping was a key aspect to this course where testing was posed as being critical to establishing analytical design skills. Each prototype involves developing a set of questions to be asked and tested and failure was as much a process for learning as it was a way to address iterative design processes. The third objective was the final realization of the project and installing on site, allowing the work to engage with different audiences.
The fabrication of the project components was all done at the FabLab at Taubman College. To avoid an extensive number of trips for project transport between Ann Arbor and Popps Packing, the students were required to assemble components as large as it would fit in a box truck, with the rest of the assembly and installation done on site. This enabled more prefabrication to take place indoors and reduce the actual time necessary for on-site building. In all, from an initial idea proposed at the end of the seminar, to the final exhibition and presentation, the projects went through design development, prototyping and testing, detailing, sourcing, construction documents, fabrication/production, site prep, installation, and documentation in a typical sixteen-week semester.

Line Weight_a novel articulation of boundary was produced by Sophie Anstreicher, Scott Chriss, Alexandre Comas, and Troy Huckendubler. This double two-person team worked collectively, not only to accomplish more than the sum of what would have been possible individually, but also to use each other's project to reinforce design intentions and experiential effects. The final result consists of two parts, a $120 \mathrm{ft}$-long fence made of robotically bent, welded $3 / 8$ " steel rod, and a series of polyurea coated foam masses are inserted and held at various locations in the fence (figure 3). The fence, stretches across four lots which mark the edge of where houses used to exist along the block. The fence faces McPherson Street with the Back Forty as the backyard lane. The choice of material and concept to boundary:

[P] lays with ideas of the definition of threshold and subverts the concept of a purely exclusionary boundary by testing the limits of porosity, transparency, and functionality in creating an edge. As an image, the steel aims to create a blurred edge condition whose reading changes with proximity and directionality. Up close, careful consideration is given to line-weight. The steel rod becomes akin to a drawing tool, taking care not to draw so boldly that it defines the edge too rigidly. ${ }^{3}$

As one moves obliquely, the steel fence gains a sense of threedimensional volume. When facing the fence perpendicularly, the fence dematerializes. The fence's perceptual quality belies its performance. It holds the edge of the property yet is extremely porous. It holds the foam solids by virtue of thin steel lines. It even gains height and thickness to provide an interior for inhabitation.

The solid foam masses work as contrast to the steel lines, stereotomically, interrupting the rhythm of the steel lines. The foam pieces are robotically hot-wire cut and coated in polyurea (truck bed liner). The coating makes the foam incredibly durable and weather proof - allowing for the pieces to be removed from the fence (its holder), to serve as outdoor furniture; stools, lounge-chairs, coolers, and planters. At strategic locations, the foam pieces act as gates for the fence. Users can arrange them in any configurations as necessary 
and placed back onto/into the fence for storage. Together, these two conceptually contrasting yet complementary projects reinforce each other's functional program. When the fence is opened, the foam gate is removed, making possible the arrangement with other pieces for a "gathering." When the fence is closed and complete, the continuity of the fence is visible to mark an edge condition.

The Sensorium by Sarah Munchow and Dakota Pahel-Short models a typical backyard shed situated at the edge of the Back Forty alley. Strategically located, the shed anchors the corner of a lot where in the future, more activities are planned around the shed. The stained plywood shed programmatically opens up to different activities, serving as storage for tools to host workshop and at night, becomes the backdrop for a stage for performances. When the shed opens up on two sides, the skin stretches across to make the volume seem much larger than its footprint. To add to the visual effect, the skin of the shed is CNC machined with undulating lines that suggest another volumetric space (figure 4).

The framing of the shed is made of dimensional lumber assembled at the shop, installed on site, then cladded with the routed panels. Non-standard hinge details were developed to create a smooth and unbroken surface when the panels are opened to give the impression of a continuous skin. The undulating lines on the skin is CNC routed with varying thickness in width/weight. Thus, the project, more than the construction of a backyard shed was about the exploration of using the $\mathrm{CNC}$ router to draw. Prototypes test the calibration between the thickness of the line registered against the depth being routed before the surface loses its constructive role as lateral bracing for the framed panels. Ultimately, a unique finishing bit with a different chamfer angle had to be used to satisfy both aesthetic and performative criteria.

The third project, Make-Ur-Space by Jaemoon Rhee and Tzu-Hsiang Lin, focused on remaking a fence edge marking the property line of one of Popps Packing's buildings that is adjacent to a public lane way for the Back Forty. Replacing a chain-linked fence, the new fence is made of two types of repeating concrete cast units that can be dry stacked and aggregated in different configurations. The concrete units are hexagonal in shape but has interlocking geometries that enables anyone to stack them to create a boundary or remove them as portable furniture (figure 5). A piece of plywood can be added to the top closing the unit when resting on the ground sideways.

The decision to remake this fence is driven not only by functional needs but also to promote social interaction. For various types of DIY building projects at Popps Packing, a truck has to be able to pull in to the backyard area. In the case of public events, the fence can be dismantled to open up the yard to bleed into the public lane way. The units can be scattered to form a 'living room' outside, encouraging people to loiter and occupy the now thicken zone of the boundary/ property line. In the static, stacked manner, the fence creates the physical boundary. When the units are dismantled, a social space is created. The scale of the units is determined by weight, whereby an adult can readily lift them but not light enough that someone can easily walk off with them. Additionally, the aperture size through the units prevents a resident dog from escaping through the fence.

The process for casting the concrete units was borrowed from metal foundry casting techniques using packed sand mixed with bentonite. The interior negative void of the unit was hand-packed into a mold, which is then removed, leaving the sand in place. The outer edge of the formwork is then added, with concrete poured in-between the sand and the outer formwork. Once the concrete is set, the sand is scooped out. This process enabled the undercut geometry of the units to be cast where traditional processes prove impossible. The molds were also reusable enable the team to cast the units with just a handful of molds. Beyond developing the process for casting, the group also developed a special recipe for the concrete mix with a plasticizer to aid flow. A colorant was added in various concentrations to create a variation in tones as the units stack to become the fence.

\section{CONCLUSION - COMMUNITY-BASED COLLABORATION + DIGITAL FABRICATION + DESIGN BUILD}

Beyond presenting a range of design parameters to contend with, the digital fabrication processes investigated by the students were novel experiments that prototyping was necessary to identify the range of issues that comes with material making. For instance, a special computational code had to be written for generating the steel components for the Line Weight fence that would not only be efficient in material use given the available $20 \mathrm{ft}$. stock length, but also to strategically locate where the rods meet for welding to ensure key moments are rigid to resist shear forces. Also, as prototypes were being evaluated after welding, tolerance became an issue as shifting occurred due to the rod's spring back from bending. Over the course of the 120-ft fence, the offset between each welded section would add up, making it out of alignment by the time it reaches the opposite end. The students then decided that it was necessary to configured an adjustable jig for welding. In this process, the students not only incorporated the behavior of the material into the design, but also confronted the issue of tolerance which is virtually nonexistent in the digital world if they had not prototyped part of their design.

This thesis course, with the integration of community-based collaboration, digital fabrication, and design build, covered a wide range of topics that are not typically taught together in a design studio setting. This included the opportunity for the students to not only engage in speculative design process with a complex set of parameters but also the chance to 


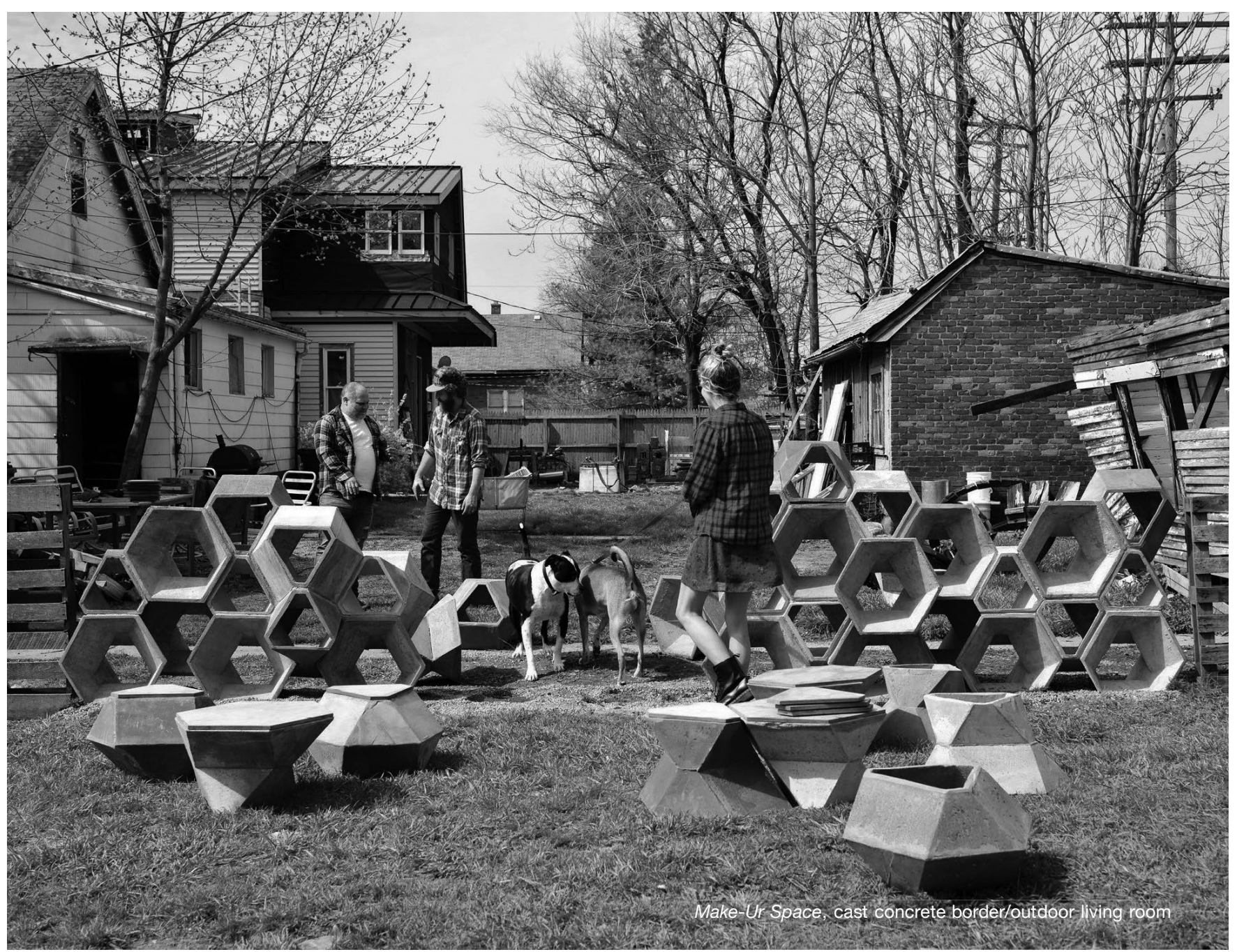

Figure 5: Make-Ur-Space, property fence consists of two types of cast concrete units

realize the project. Also, while these three aspects may show up at various moments as part of an architectural education, they are often taught in isolation. The success of the course's framing lies precisely in how these areas could opportunistically overlap to inform one another and offer moments of learning that is not strictly prescriptive. The linking of the thesis studio with an advanced digital fabrication course not only provides a valuable exposure to contemporary techniques and processes for making, it also presents students an opportunity to interrogate their designs against the exigencies of site, community, and program.

\section{ENDNOTES}

1. Eyal Weizman, "Introduction," in Forensis: The Architecture of Public Truth (Berlin: Sternberg Press, 2014), 9.

2. Funding was made possible by a Michigan Mellon Project on Egalitarianism collaboration with Joan Kee for interdisciplinary teaching. Additional support was received from Taubman College of
Architecture, University of Michigan.

3. Excerpt of project description by the students. 